\title{
Current and Novel Methods in Clinical Microbiology: Advantages and Pitfalls when Facing the Menace of Antimicrobial Resistance
}

\author{
Pina-Vaz $\mathbf{C}^{1,2^{*}}$, Azevedo MM ${ }^{1,2}$ and Rodrigues AG ${ }^{1,2,3}$ \\ ${ }^{1}$ Faculty of Medicine, Department of Microbiology, University of Porto, Portugal \\ ${ }^{2}$ Faculty of Medicine, Center for Health Technology and Services Research (CINTESIS), University of Porto, Portugal \\ ${ }^{3}$ Department of Microbiology, Centro Hospitalar S. João, Portugal
}

*Correspondig author: Pina-Vaz C, Faculty of Medicine, Center for Health Technology and Services Research (CINTESIS), University of Porto, 4200-319 Porto, Portugal, Tel: 00351 924393147; E-mail: cpinavaz@med.up.pt

Rec: Feb 15, 2018, Acc: Mar 05, 2018, Pub: Mar 09, 2018

Copyright: ( 2018 Pina-Vaz C, et al. This is an open-access article distributed under the terms of the Creative Commons Attribution License, which permits unrestricted use, distribution, and reproduction in any medium, provided the original author and source are credited.

\begin{abstract}
Microbiological clinical methods were the object of this review. According to WHO antimicrobial resistance is a real and global threat. Researchers aim to develop rapid methods for identification and antimicrobial susceptibility (AST). Actually, most automated solutions available in clinical laboratories are based upon the study of the microbial ability to grow so, take a long time to give results despite its advantages. Molecular tests only detect target genes but are especially useful regarding identification of difficult or slow growing microorganisms. MALDI-TOF started a real revolution in microbial identification since it is growth independent and highly sensitive and specific. Regarding susceptibility evaluation, due to its inherent complexity, molecular or proteomic tests provides answers to known and molecular characterized mechanisms, requiring its prior knowledge. Flow cytometry is an excellent tool that, coupled with specific fluorescent antibodies can be used to identify microorganisms. Moreover, it can help to unveil susceptibility profile. AST phenotype is provided following incubation of the cells for short period (60 minutes) with antimicrobial drugs and fluorescent probes, with excellent correlation with classic AST methods. Furthermore, it can elucidate about the most relevant mechanism of resistance in a functional assay. Novel methods are under study namely sophisticated methods for growth detection like, weighing bacteria by vibrating cantilevers, isothermal microcalorimetry method, simple spectroscopic biomarkers and plasmonic imaging and tracking are discussed. We are close to a change of the paradigm in the clinical laboratory work flow microbiology considering especially MALDI-TOF for identification and flow cytometry for AST/assessment of mechanisms of resistance.
\end{abstract}

Keywords: Methods in Microbiology; Antimicrobial resistance; MALDI-TOF; Molecular methods; Flow cytometry

\section{Introduction}

According to WHO antimicrobial resistance is manifesting at a global level, compromising our ability to treat infectious diseases, as well as undermining many other advances in health and medicine. To combat this menace, a global action plan set out several strategic objectives, including the development of new antimicrobial drugs, epidemiological data tools and stewardship programmers and new diagnostic methods, namely faster susceptibility tests. Reducing the lab test time-to-result can have considerable impact in target treatment and timely isolation of positive patients, which can play a vital role in hospital infection prevention and control [1]. Particularly during an outbreak, the impact of rapid diagnostics can be substantial and directly influence infection control and treatment options as well as having a strong positive financial effect on health care.

Clinical microbiology, as most of other Laboratory sectors, incorporated on its routine a lot of automated methods, which allowed the increase of performance of lot of tests in a short time, reduced the number of technical errors and introduced huge software possibilities of data analysis. Interestingly most of the microbiology technology used at this moment involves automatization of the conventional manual procedures. Most often, there is the need of culture of the biological samples such as blood, urine, respiratory secretions, in order to isolate the organisms in pure culture, which takes at least 24 hours.

\section{Literature Review}

\section{Current automated methods}

Regarding microbial identification, the automated antimicrobial methods more widely used are Vitek from Bio Mérieux, Dade Behring from Sysmex or Phoenix from Beckton Dickinson, which are based on the study of the microbial phenotypical behavior in the presence of different subtracts. Despite the increasing number of biochemical tests performed on those equipment's, turning them more accurate, automated and less subjective, they are somewhat similar to the tests primary performed using macro tubes or even with miniature galleries. They require incubation, like the manual tests, which takes time. However, the result is automatically obtained comparing with the software database.

Regarding antimicrobial susceptibility (AST), the same automated equipment's are able to perform based upon the study of the ability of the microorganism to replicate in the presence of different antimicrobials. Automated AST is based upon spectrometry technology to detect growth. Either manual or automated methods need time to incubate the microorganisms, being the result automatically given on the automated methods. Although the 
reference method is a manual method (microdilution) a good correlation between results of methods is obtained.

The software of automated equipment's has huge potentialities such as the possibility to correct technical errors, to make programmed alarms or to make epidemiological studies periodically, providing important hints to guide empiric antibiotic therapy. Identification and susceptibility profile takes, from pure culture around 24 hours so only after a minimum of 48 hours after sample collection the result of identification and susceptibility profile is provided to the clinician.

\section{Molecular methods}

Molecular diagnostics created a revolution on many science and medical fields and was also applied to clinical diagnostics. This technology brings a different paradigm on detection and identification of microorganisms, including the detection of selected genetic resistance mechanisms, quite important in clinical decision and infection prevention. It could be applied to isolated microbial colonies but also directly to the biological product. As is not based upon the ability to replicate much faster results are obtained. However, the diagnosis could be performed only if we look for previous selected targets. This is especially important when conventional methods are inaccessible for example in case of uncultivable or slow growing microorganisms like virus or Mycobacterium. Positive results do not mean viability so, molecular methods should not be used during the follow-up of the treatment. Regarding AST, the absence of a certain resistance market does not mean susceptibility; for instance, the absence of mecA gene does not mean that we are facing an MSSA ( $S$. aureus methicillin susceptible); the recent description of mecC that also codifies for MRSA is a living proof [2]. Regarding $B$ lactamases, representing an enzymatic mechanism of resistance quite important towards the beta-lactamic drugs, several genes were found to be involved. In case of a positive result we know that we are facing a resistant strain due to an ESBL or carbapenemase but, in case of a negative result we cannot assume the strain as susceptible. More recently, a nucleic acid microarray was described for the detection of ESBL/KPC, with high sensitivity and specificity [3].

A procedure based on real-time PCR has been developed to determine the antimicrobial susceptibility by monitoring pathogenic load with the highly conserved 16S rRNA gene in blood samples exposed to different antimicrobial drugs [4]. This method combines rapid molecular diagnostic detection with the traditional benefits of phenotypic testing to achieve universal susceptibility analysis, minimum inhibitory concentration determination and pathogen identification in the blood in around 9 hours.

\section{Immunological methods}

Immunological methods allow the detection of antigens and/or antibodies and are especially useful when the culture is unable or difficult such as on sifilis or legionella as example of bacterial infection or in all kinds of virus infections. Automated methods such as ELISA or quemiluminescence are easy to use and exhibit high sensitivity and specificity. Immunofluorescent methods also showed excellent results but are more manual needing experience on the observation. However, these methods reveal similar limitations as we found on molecular methods. They are also target methods, so we only find what we are looking for. Regarding AST/mechanisms of antimicrobial resistance few tests were developed such as the immune chromatographic method for the presence of PBP2A on MRSA [5].

\section{Matrix-Assisted Laser Desorption Ionization-Time of Flight mass spectrometry (MALDI-TOF)}

Mass spectrometry (MS) is an old technique that only recently being used on Microbiology. The chemical species are ionized, and the ions are sorted based on their mass-to-charge ratio. In simpler terms, a mass spectrum measures the masses within a sample. Mass spectrometry is used in many different fields and can be applied to pure samples as well as complex mixtures.

Mass spectrometry is an important method for the characterization and sequencing of proteins. In keeping with the performance and mass range of available mass spectrometers, two approaches are used for characterizing proteins. During the recent years, applications of MS for microbial characterization in research, clinical microbiology, counterbioterrorism, food safety, and environmental monitoring have been documented in thousands of publications. As of mid-2015, more than 3300 commercial MS systems for microbial identification have been deployed worldwide in hospitals and clinical labs.

Very fast results can be obtained (in few minutes) from pure colonies and more recently directly from positive blood cultures. Promising results are also obtained from other clinical samples such as urine. Since targets are not needed, it is an open diagnostic method and represents a real progress on the lab diagnosis. The big difference from genetic methods is that proteomic techniques do not focus on a single gene.

The identifications of proteins are commonly performed by MALDI-TOF MSor MALDI-tandem TOF [6]. Regarding AST/ antimicrobial resistance mechanisms several approaches have been explored [7] by Hrabak, 2013, including:

- Looking for the integrity of the antimicrobial drug due to enzyme degradation such as: Beta-lactamases or carbapenemases. Different subtract (carbapenems) gives different results [8] and different incubation times are needed to detect the presence of different enzymes [9]. Besides that, some molecules degraded spontaneously during the incubation time.

- The detection of modifications on rRNA by MALDI-TOF MS allowed the detection of the methylation of $23 \mathrm{~S}$ rRNA by the product of the cfr gene, which is responsible for resistance to chloramphenicol, florfenicol, and clindamycin. For that analysis, however, it was necessary to use purified ribosomes and purified enzymes turning the process more complex [10].

- Changes in the protein spectrum of an organism, in the presence or absence of an antimicrobial agent, correlates with susceptibility changes.

The detection of MRSA using MALDI-TOF was comparable to molecular detection of gene mecA [11] and although it is necessary some processement of the sample it is similar to molecular biology methods.

Confirming the presence of some antimicrobial resistance was also possible under MALDI-TOF MS after a standard formic acid extraction method, such as the detection of the presence of the gene $\operatorname{van} A[12]$.

However antimicrobial resistance is such a complex phenomenon that it will be very difficult, if not impossible, through genetic or proteomic to address comprehensibly such a difficult and vast topic.

In fact, although molecular techniques as well as MALDI-TOF can correlate well with certain specific mechanisms of antimicrobial 
resistance, both do not provide enough information about susceptibility pattern which, could guide a clinician in therapeutic decision.

\section{Flow cytometry}

Flow cytometry (FC) represented a revolution on cytology, haematology and oncology fields and only more recently was applied with great advantages to microbiology [13].

Using specific fluorescent antibodies, FC can be used for microbial identification as a target method similar to other antigen/antibodies tests. Such an approach is especially important regarding Legionella pneumophilla detection in water or biological samples [14] or fungi such as Pneumocystis [15]. Regarding parasites FC was useful for detection of Cryptosporidium [16] Encephalitozoon intestinalis [17] or Giardia lamblia [18].

Regarding AST a EU and European pattern [19] describe the method for susceptibility evaluation from isolated colonies but also from blood cultures (after positive flag), cerebrospinal fluid and urine (after screening for positivity). The concept involves the detection of morpho-functional changes in the microorganisms after exposing to different antimicrobial drugs for short periods of time (60 minutes). Different protocols were designed, according to the type of microorganism, Gram positive or Gram negative, and the different antimicrobial drugs. Different fluorescent probes were selected in order to provide the better discrimination between susceptible, intermediate and resistant phenotypes. Different probes in different microorganisms could behave in different ways. A flow cytometric protocol was designed and an excellent correlation with the reference manual method was found. After analyzing a large number of susceptible and resistant phenotypes a dedicated software was developed in order to obtain the pattern automatically [13]. Additionally, to the phenotype, flow cytometry assays could elucidate about the mechanism of antimicrobial resistance like resistance to beta-lactamase drugs due to enzymes such as ESBL [20] or carbapenemases [21] in 60 minutes which represents a considerable step forward. They were based on the EUCAST protocol (mechanisms of resistance 2017) basically involving the addition of the different inhibitors to the beta-lactamase drugs and re-testing the organism. Only with rapid diagnostic tests prevention attitudes could be made in useful time avoiding the spread of resistant microorganisms. We have been using 60 minutes incubation time to analyses several drugs regarding different microorganisms but for some specific drugs shorter incubation times are enough.

As flow cytometric analysis is not growth dependent, it brings several advantages. Apart from being more rapid it also could be used on fastidious microorganisms like Haemophilus influenzae or Streptococcus pneumoniae. Regarding other microorganisms like microaerophilic such as Campylobacter or even anaerobes this approach as also feasible.

\section{Advanced microscopy and mixed techniques}

Closer to the market and already approved by FDA is the Accelerate Pheno System (Accelerate Diagnostic). It is a fully automated system that performs both identification and antimicrobial susceptibility testing directly from positive blood culture within $7 \mathrm{~h}$. The system combines gel electrofiltration and fluorescence in situ hybridization for bacterial identification as well as automated digital microscopy for analyzing bacterial growth rates. The availability of rapid identification and AST results in bloodstream infections has a great impact on patient outcome and length of hospital stay as well as on the effectiveness of antibiotic stewardship programs [22].

Several techniques are under development mainly based on the ability of early detection of microbial growth.

Image based tools such as multiplexed automated digital microscopy (MADM), single-cell morphological analysis (SCMA) and oCelloscope have been described as automated techniques for AST. Although they shorten the detection time from days to a few hours (6 h), these technologies still use replication-dependent methodologies that have a primary culture step (e.g. growth from a blood culture bottle or growth on a primary culture plate) $[23,24]$.

\section{Discussion}

\begin{tabular}{|c|c|c|c|c|c|}
\hline Method & ID/AST & $\begin{array}{l}\text { Time-to- } \\
\text { result }\end{array}$ & $\begin{array}{l}\text { Patient } \\
\text { sample or } \\
\text { BC }\end{array}$ & $\begin{array}{l}\text { FDA } \\
\text { approval }\end{array}$ & Reference \\
\hline \multirow[t]{2}{*}{ Molecular } & \multirow[t]{2}{*}{ Yes/yes } & \multirow[t]{2}{*}{$4-9 h$} & \multirow[t]{2}{*}{ Yes } & \multirow[t]{2}{*}{ Yes } & $\begin{array}{l}\text { Fishbain et } \\
\text { al. }\end{array}$ \\
\hline & & & & & $\begin{array}{l}\text { Waldeisen } \\
\text { et al. }\end{array}$ \\
\hline \multirow{3}{*}{$\begin{array}{l}\text { MALDI- } \\
\text { TOF }\end{array}$} & \multirow[t]{3}{*}{ Yes/yes } & \multirow[t]{3}{*}{$3-5 h$} & \multirow[t]{3}{*}{ Yes } & \multirow[t]{3}{*}{ Yes } & Shar et al. \\
\hline & & & & & $\begin{array}{l}\text { Syrmis et } \\
\text { al }\end{array}$ \\
\hline & & & & & $\begin{array}{l}\text { Kirpekar et } \\
\text { al. }\end{array}$ \\
\hline Accelerate & Yes/yes & $7 \mathrm{~h}$ & Yes & Yes & $\begin{array}{l}\text { Marshall et } \\
\text { al. }\end{array}$ \\
\hline \multirow{2}{*}{$\begin{array}{l}\text { Image } \\
\text { based tools }\end{array}$} & \multirow[t]{2}{*}{ No/yes } & \multirow[t]{2}{*}{$1-5 h$} & \multirow[t]{2}{*}{ Yes } & \multirow[t]{2}{*}{ No } & Karan et al. \\
\hline & & & & & Choi et al. \\
\hline \multirow[t]{2}{*}{ Cantilevers } & \multirow[t]{2}{*}{ No/yes } & \multirow[t]{2}{*}{$<2 \mathrm{~h}$} & \multirow[t]{2}{*}{ No } & \multirow[t]{2}{*}{ No } & $\begin{array}{l}\text { Godin et } \\
\text { al., Kasas } \\
\text { et al. }\end{array}$ \\
\hline & & & & & $\begin{array}{l}\text { Longo et } \\
\text { al. }\end{array}$ \\
\hline PIT & No/YES & $<2 \mathrm{~h}$ & Yes & No & Syal et al. \\
\hline SERS & \multirow[t]{2}{*}{ No/YES } & \multirow[t]{2}{*}{$2 \mathrm{~h}$} & \multirow[t]{2}{*}{ No } & \multirow[t]{2}{*}{ No } & $\begin{array}{l}\text { Chia-Ying, } \\
2015 ; \\
\text { Smolsky et } \\
\text { al. }\end{array}$ \\
\hline $\begin{array}{l}\text { Real-time } \\
\text { PCR 16S } \\
\text { RNA }\end{array}$ & & & & & $\begin{array}{l}\text { Waldeisen } \\
\text { et al. }\end{array}$ \\
\hline IMC & No/Yes & $3-14 \mathrm{~h}$ & Yes & No & $\begin{array}{l}\text { Von et al. } \\
2009 \text {, } \\
\text { Braissant } \\
\text { et al. }\end{array}$ \\
\hline FC & Yes/yes & $1 \mathrm{~h}$ & Yes & No & $\begin{array}{l}\text { Pina-Vaz et } \\
\text { al. }\end{array}$ \\
\hline
\end{tabular}

Table 1: Current and novel methods in clinical microbiology. 


\section{New technologies}

In a more distant future regarding AST applications since being still under development several methods could be listed.

Microbial cell weighing with and without antibiotic treatment by vibrating cantilevers allows the distinction between susceptible from resistant strains in short time $(<2 \mathrm{~h})[25,26]$. Bacteria passing cantilevers with small canals will cause a change in the frequency of cantilever movement. Cells treated with antimicrobials will change their buoyant mass density and this will be measured [27] (Table 1).

Isothermal microcalorimetry (IMC) will measure the heat production from the metabolism of keenly growing bacteria and a correlation with the growth curve- lag, log and stationary phases was made $[28,29]$. Since the lower limit of detection for IMC is $\sim 10^{4}$ $\mathrm{cfu} / \mathrm{ml}$, the approach enables faster AST. Three a 14 hour is needed to give results and can be used directly from some biological products. Rotating magnetic ligand-modified beads driven by a revolving magnetic field would change the frequency of rotation by the binding of bacteria. According the bacteria phenotype the rotation frequency change, indicating the effectiveness of the antibiotic [28].

Recently the discovery of simple spectroscopic (SERS) biomarkers for bacterial AST was described. A change in the bacterial SERS spectra in response to antibiotic treatment for 2 hours is a promising method despite still not well understand [30]. This technique was described to detect different biomarkers for several disorders [31]. It can be used to monitor bacterial activity and simultaneously confers spectroscopic specificity.

A plasmonic imaging and tracking (PIT) technique has been used to track 3D motions of single bacterial cells associated with metabolic viability, thus leading to rapid AST [32]. PIT could potentially be used to spatially resolve and identify bacterial cells even in a complex matrix of urine, serum, and other body fluid samples, which is critical for developing PIT into a practical solution for testing real patient samples. AST could take less than $2 \mathrm{~h}$.

\section{Conclusion}

Most methods under current use or in development in Microbiology despite being old in other scientific areas are new in Microbiology.

The possibility of real-time AST tools would not only help to save lives but would also have the potential to enable targeted antibiotic treatment at disease onset, potentially slowing the evolution of antibiotic resistance and improving antibiotic stewardship. Given the ever-increasing spread of antibiotic resistance, researchers much develop innovative technologies, which could allow rapid microbiological diagnostic within an hour, to be applied to samples collected directly from the patient, either sterile or contaminated biological products. Only after achieving such a goal, a real valuable antimicrobial policy could be implemented allowing the prescription of targeted and safer therapy, reducing morbid-mortality and avoiding the spread of the infection. In our opinion in a near future the paradigm of microbiological diagnostics can change. MALDI-Tof for identification and flow cytometry for AST and clarification of main mechanisms of resistance directly from positive blood cultures, urine and isolated microbial colonies could give a real contribution to clinical diagnostics and help to save lives.

\section{Acknowledgments}

C Pina Vaz and AG Rodrigues are co-founders of FASTinov, a spinoff of Porto University. No further potential conflicts of interest relevant to this article are reported.

\section{References}

1. Dik JH, Poelman R, Friedrich AW, Niesters HGM, Rossen JWA, et al. (2017) Integrated Stewardship model comprising antimicrobial, infection prevention, and diagnostic stewardship (AID Stewardship). J Clin Microbiol 55: 3306-3307.

2. Paterson GK, Harrison EM, Holmes MA (2014) The emergence of mecC methicillin-resistant Staphylococcus aureus. Trends Microbiol 22: 42-47.

3. Fishbain JT, Sinyavskiy O, Riederer K, Hujer AM, Bonomo RA (2012) Detection of extended-spectrum $\beta$-lactamase and Klebsiella pneumoniae Carbapenemase genes directly from blood cultures by use of a nucleic acid microarray. J Clin Microbiol 50: 2901-2904.

4. Waldeisen JR, Wang T, Mitra D, Lee LP (2011) A real-time PCR antibiogram for drug-resistant sepsis. PLos One 6: e28528.

5. Bignardi GE, Woodford N, Chapman A, Johnson AP, Speller DC (1996) Detection of the mec-A gene and phenotypic detection of resistance in Staphylococcus aureus isolates with borderline or low-level methicillinresistance. J Antimicrobial Chemother 37: 53-63.

6. Shah H, Gharbia S (2010) Mass spectrometry for microbial proteomics. United Kingdom: John Wiley and Sons, Inc, Chichester.

7. Hrabák J, Chudácková E, Walková R (2013) Matrix-assisted laser desorption ionization-time of flight (Maldi-Tof) mass spectrometry for detection of antibiotic resistance mechanisms: from research to routine diagnosis. Clin Microbiol Rev 26: 103-114.

8. Hooff GP, van Kampen JJ, Meesters RJ, van Belkum A, Goessens WH, et al. (2012) Characterization of $\beta$-lactamase enzyme activity in bacterial lysates using MALDI-mass spectrometry. J Proteome Res 11: 79-84.

9. Hrabák J, Walková R, Studentová V, Chudácková E, Bergerová T (2011) Carbapenemase activity detection by matrix-assisted laser desorption ionization-time of flightmass spectrometry. J Clin Microbiol 49: 3222-3227.

10. Kirpekar F, Douthwaite S, Roepstorff P (2000) Mapping posttranscriptional modifications in $5 \mathrm{~S}$ ribosomal RNA by MALDI mass spectrometry. RNA $6: 296-306$.

11. Syrmis MW, Moser RJ, Whiley DM, Vaska V, Coombs GW, et al. (2011) Comparison of a multiplexed MassARRAY system with real-time allelespecific PCR technology for genotyping of methicillin-resistant Staphylococcus aureus. Clin Microbiol Infect 17: 1804-1810.

12. Griffin PM, Price GR, Schooneveldt JM, Schlebusch S, Tilse MH, et al. (2012) Use of matrix-assisted laser desorption ionization-time of flight mass spectrometry to identify vancomycin-resistant enterococci and investigate the epidemiology of an out- break. J Clin Microbiol 50: 2918-2931.

13. Pina-Vaz C, Costa-de-Oliveira S, Silva-Dias A, Silva AP, Teixeira-Santos R, et al. (2017) Flow cytometry in microbiology: The Reason and the Need. In: Robinson JP, Cossarizza A, (eds). Single Cell Analysis. Series in Bio Engineering pp. 153-170.

14. Faria-Ramos I, Costa-de-Oliveira S, Barbosa J, Cardoso A, SantosAntunes J, et al. (2012) Detection of Legionella pneumophila on clinical samples and susceptibility assessment by flow cytometry. Eur J Clin Microbiol Infec Dis 31: 3351-3357.

15. Barbosa J, Bragada C, Costa-de-Oliveira S, Ricardo E, Rodrigues AG, et al. (2010) A new method for the detection of Pneumocystis jirovecci using flow cytometry. Eur J Clin Microbiol Infec Dis 29: 1147-1152.

16. Barbosa JM, Costa-de-Oliveira S, Rodrigues AG, Hanscheid T, Shapiro H, et al. (2008) A flow cytometric protocol for detection of Cryptosporidium spp Cytometry A 73: 44-47. 
Citation: Pina-Vaz C, Azevedo MM and Rodrigues AG (2018) Current and Novel Methods in Clinical Microbiology: Advantages and Pitfalls when Facing the Menace of Antimicrobial Resistance. J Med Microb Diagn 7: 275. doi:10.4172/2161-0703.1000275

Page 5 of 5

17. Barbosa J, Rodrigues AG, Pina-Vaz C (2009) Cytometry approach for detection of Encephalitozoon intestinalis, an emergent agent. Clin Vaccine Immunol 16: 1021-1024.

18. Barbosa J, Costa-de-Oliveira S, Rodrigues AG, Pina-Vaz C (2008) Optimization of a flow cytometry protocol for detection and viability assessment of Giardia lamblia. Travel Med Infect Dis 6: 234-239.

19. Patent W0201264547A1. Pina-Vaz C, Rodrigues AG, Ramos I, TeixeiraSantos R, Morais AS, Silva AT. Kit and method of detecting the resistant microorganisms to a therapeutic agent.

20. Faria-Ramos I, Espinar MJ, Rocha R, Santos-antunes J, Rodrigues AG, et al. (2013) A novel flow cytometric assay for rapid detection of extendedspectrum betalactamases. Clin Microbiol Infect 19: E8-E15.

21. Silva AP, Faria-Ramos I, Ricardo E, Marcos Miranda I, Espinar MJ, et al. (2016) Rapid flow cytometry test for identification of different carbapenemases in Enterobacteriaceae. AAC. Antimicrob Agents Chemother 60: 3824-3838.

22. Marschal M, Bachmaier J, Autenrieth I, Oberhettinger P, Willmann M, et al. (2017) Evaluation of the accelerate pheno system for fast identification and antimicrobial susceptibility testing from positive blood cultures in bloodstream infections caused by gram-negative pathogens. J Clin Microbiol 55: 2116-2126.

23. Syal K, Mo M, Yu H, Iriya R, Jing W, et al. (2017) Haydel, Nongjian Tao. Current and emerging techniques for antibiotic susceptibility tests. Theranostics 7: 1795-1805.

24. Choi J, Jeong HY, Lee GY, Han S, Jin B, et al. (2017) Direct, rapid antimicrobial susceptibility test from positive blood cultures based on microscopic imaging analysis. Sci Rep 7: 1148.
25. Godin M, Delgado FF, Son S, Grover WH, Bryan AK, et al. (2010) Using buonyant mass to measure the growth of single cells. Nat Methods 7: 387-390.

26. Kasas S, Ruggeri FS, Benadiba C, Maillard C, Stupar P, et al. (2015) Detecting nanoscale vibrations as signature of life. Proc Natl Acad Sci U S A 112: 378-381.

27. Longo G, Alonso-Sarduy L, Rio LM, Bizzini A, Trampuz A, et al. (2013) Rapid detection of bacterial resistance to antibiotics using AFM cantilevers as nanomechanical sensors. Nat Nanotechnol 8: 522-526.

28. von Ah U, Wirz D, Daniels AU (2009) Isothermal micro calorimetry- a new method for MIC determinations: results for 12 antibiotics and reference strains of Escherichia coli and Staphylococcus aureus. BMC Microbiol 9: 106.

29. Braissant O, Bachmann A, Bonkat G (2015) Microcalorimetric assays for measuring cell growth and metabolic activity: Methodology and applications. Methods 76: 27-34.

30. LiuC, Han Y, Shih P, Lian W, Wang H, et al. (2016) Rapid bacterial antibiotic susceptibility test based on simple surface-enhanced Raman spectroscopic biomarkers. Scientific Reports 6: 23375.

31. Smolsky J, Kaur S, Hayashi C, Batra SK, Krasnoslobodtsev AV (2017) Surface-enhanced raman scattering-based immunoassay technologies for detection of disease biomarkers. Biosensors (Basel) 7.

32. Syal K, Wang W, Shan X, Wang S, Chen HY, et al. (2015) Plasmonic imaging of protein interactions with single bacterial cells. Biosens Bioelectron 63: 131-137. 